\title{
Risk Decision for Dual-Channel Supply Chain of Agricultural Products Under Disturbance
}

\author{
Yijian Liu(1),(2), Yehua Chen(1) \\ (1) School of Economics and Management, Yanshan University, Qinhuangdao, CHINA \\ (2) Hebei Normal University of Science \& Technology, Qinhuangdao, CHINA
}

\section{SUMMARY}

This paper presents a decision analysis model for the dual-channel supply chain of agricultural products under the disturbance of emergency. Mean variance analysis tool and utility function risk tool are used to describe risk indicators in supply chain. In this study, retailer plays a leading role in agricultural supply chain. By means of the Kuhn-Tucker condition of the retailer's maximum utility, the optimal price and optimal demand are obtained. The study also shows that risk averse retailer has higher wholesale price, lower retail price and greater supply as well as the demand for the pursuit of greater utility; Supplier has a certain robustness to the sudden event disturbance, when the disturbance is large, the quantity of initial supply quantity will be adjusted. The relationship between the demand change rate of the two channels and the market share of the channel is found. Finally, some numerical examples are presented to illustrate the results. The study provides a possible way of thinking in emergency decision analysis.

KEY WORDS: dual-channel supply chain; risk decision making; emergency.

\section{INTRODUCTION}

Markets and retail stores are traditional channels for people to buy agricultural products. With the development of e-commerce, internet of things and transportation, direct marketing channels are gradually accepted by more and more people. Suppliers often use dual-channel sales mode which is online direct selling and traditional retailing. Cai et al. studied the impact of channel structure and channel coordination on suppliers and pointed out that suppliers and retailers benefited from the new channel of traditional single channel supply chain [1]. Pu et al. compared the operating efficiency of single-channel agricultural products model and doublechannel model, and found that the profit level of the double-channel model was higher [2]. Many governments have issued policies to encourage the development of agricultural products circulation and direct supply services, promoting, further on, the development of the dualchannel supply chain of agricultural products. 
Dual-channel problem has been extensively researched in the literature from various aspects, such as production and inventory strategies, market demand, advertising, service, lead time, and fairness concerns, coordination of the dual-channel supply chain, and pricing strategy. Li et al. considered the impact of a dominant retailer on the market retail price along with the sales promotion opportunity and examined how the manufacturer can coordinate such a supply chain by revenue-sharing contract after demand disruptions [3]. Xie et al. studied the coordination of the dual-channel supply chain in terms of the price mechanism when the manufacturer's production cost was disturbed [4]. Zhang et al. studied the coordination of the dual-channel supply chain in the case of interference [5].

In recent decades, typhoons, earthquakes, fires, terrorist attacks, financial crises, food safety incidents and other disasters have occurred frequently all over the world disrupting the normal operation of the supply chain and causing the disturbance of market demand. Agricultural product supply chain is more vulnerable to unpredictable circumstances because of the products nature [6]. The output and demand of agricultural products are random, so the supply and demand mismatch often occurs. For example, in 2010, the winter drought in the nine provinces of northern China reduced the yield of wheat to significant degrees, and the quality was also affected; streptococcus infection caused a serious decline in the demand for pork in a short period of time; the sudden outbreak of bird flu (H7N9) caused a decline in poultry demand. Food safety accidents happen constantly, threatening people's health seriously, and causing people to rise or reduce product demand.

More and more attention is being paid to supply chain risk management. Risk management has a great influence on the stability of dynamic cooperations and supply chain partners which makes it very important for the performance of the supply chain operations as a whole. Supply chain risk management can use quantitative analysis methods such as game theory, queuing theory, linear programming, nonlinear programming, multi-object optimization, Markov decision process, the conditional value at risk (CVaR) analysis method, the mean variance analysis tool, fuzzy mathematics, etc. Risk management of supply chain is relatively new research field and there is a big research area to be developed. Sarykalin et al. established a mathematical model to minimize the risk loss from the mathematical point of view of mathematics with the help of conditional value at risk (CVaR) analysis [7]. Wang discussed the two level supply chain collaboration incentive problems that include the risk-averse of both the retailers and the suppliers [8]. Sawik studied the risk-averse decision-making model for risk management of supply chain [9]. Literature [8, 9] generally considers the decision risk of the single channel supply chain. Cao studies the retailer`s aversion risk characteristic and the remanufacturing closed loop supply chain network equilibrium problem [10]. Yan used the mean variance model to study separately the aversion risk within the dual-channel supply chain, and analyzed the impact of risk tolerance on the pricing decisions of manufacturers and retailers [11]. Li et al. studied the dual-channel supply chain with the neutral manufacturer and risk averse retailer, and the Nash equilibrium problem of wholesale price, retail price and order quantity, found that when the demand uncertainty obeys the uniform distribution, the Nash bargaining equilibrium exists, and the retail price decreases with the retailer's risk aversion [12]. Liu et al. focused on retailers in dual-channel supply chain considering the aversion risk attitude and discussed the coordination problem of supply chain [13]. Wang et al. used mean variance method to analyze the optimal pricing of dual-channel supply chain under decentralized decision making, and also studied the aversion risk of participants and the influence of market demand variance on each quantity decision [14]. Xu et al. explored the impact of risk preference on dual-channel supply chain decision-making, and established a dual- 
channel supply chain pricing decision model based on the conditional risk value (CVaR) criterion [15]. Literature [10-15] pays more attention to the study of risk preference decision makers' pricing decisions for dual-channel supply chain and does not consider the decision making risk of supply chain for unexpected emergency in general.

The contributions of this paper are as follows: we consider the agricultural dual-channel supply chain as the research object, taking the retailer with aversion risk to play a leading role in the supply chain, in response to national policy, which can improve the circulation efficiency of agricultural products, reduce the loss, avoid effectivly the phenomenon "difficult to buy, hard to sell". When unexpected events lead to demand disturbance, by means of the Kuhn-Tucker condition of the maximum utility of the supply chain system, the optimal price and optimal demand of supply chain are analysed, so with the supply chain decision-making the risk can be avoided effectively, guaranteeing the efficient, responsive and flexible operation of the supply chain of agricultural products.

\section{MODEL DESCRIPTION}

The operation mode of dual-channel regarding the participants can be divided into two types, either with the supplier as the main part of the dual-channel supply chain or the retailer as the main part. In agricultural products' supply chain, the agricultural retailer can be some large supermarket chain or a leading enterprise, tending to play a leading role in the supply chain where the supplier generally supplies the marketing center with agricultural products. This paper studies dual-channel supply chain operation based on retailer as the main part.

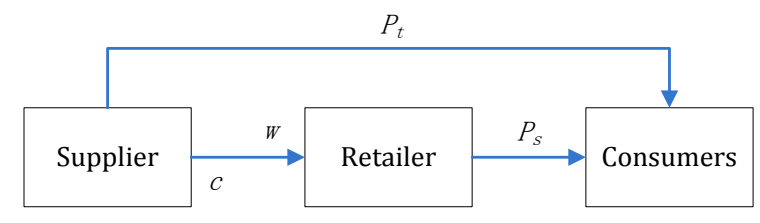

Fig. 1 Dual channel supply chain of agricultural products

Similar to the study of Huang et al. [16], it is assumed that the demand function of the retail selling channel is $D_{s}=(1-\delta) a-b_{1} P_{s}+\theta_{1} P_{t}$ and the demand function of the direct selling channel is $D_{t}=\delta a-b_{2} P_{t}+\theta_{2} P_{s}$, both being the linear functions, as shown in Figure 1 . The basic need of consumers is $D=D_{\boldsymbol{s}}+D_{\boldsymbol{t}}=a-\left(b_{1}-\theta\right) P_{s}-\left(b_{2}-\theta\right) P_{\boldsymbol{t}}$, the parameters $\delta(0<\delta<1)$ is the market share of direct channel, $b_{1}$ and $b_{2}$ are their own price elasticity respectively, $\theta_{i}(i=1,2)$ is the cross price elasticity coefficient, according to the characteristics of dual-channel mode assumption $\theta_{1}=\theta_{2}=\theta, \quad \theta<b_{1}<b_{2}$, assuming that $P_{t}>w$, otherwise the retailer will be concealed as the buyer of the supplier. The model is solved based on the following assumptions:

(1) The retailer can only purchase goods from the supplier at the wholesale price.

(2) The information among supply chain members is assumed to be completely open.

(3) The situation of free ride will not be considered.

(4) In order to simplify the calculation, so that the analysis results will not be effected, selling cost, logistics cost, service cost et al. are made zero.

(5) The loss in the storage and transportation of agricultural product will not be considered. 
In the following discussion, the symbol " " will mark the optimal strategy of a supply chain after the disruptions.

To simplify the expression, the parameters are set in the following way:

$$
\begin{gathered}
\phi=b_{1}+b_{2}-2 \theta, \varphi=\frac{\left(b_{1}^{2}+2 b_{1} b_{2}-2 b_{1} \theta-\theta^{2}\right)}{\left(b_{1}+\theta+b_{1} \delta-\theta \delta\right)}, \\
\delta_{0}=\frac{\left(b_{2}-\theta\right)}{\left(b_{1}+b_{2}-2 \theta\right)}, \quad \xi_{1}=b_{1}^{2}+2 b_{1} b_{2}-2 b_{1} \theta-\theta^{2}, \quad \xi_{2}=b_{1}+\theta+b_{1} \delta-\theta \delta .
\end{gathered}
$$

\section{RISK DECISION OF DUAL-CHANNEL UNDER STEADY STATE}

Under steady state, we consider the consumer demand to be stable. The retailer occupies the leading position in the dual-channel supply chain of agricultural products with stronger pricing power. This ensures high quality and inexpensive agricultural products and greater access to consumers on one hand and on the other the retailer price is ensured by reducing supplier's agricultural profit margin, causing the order wholesale price of retailer $w$ to be low. Considering the retailer's wholesale price and the market situation, supplier then makes the optimal wholesale price $w$ and direct selling price $p_{t}$.

The expected returns of supplier and retailer are respectively:

$$
\begin{gathered}
E\left(\pi_{a}\right)=(w-c) D_{s}+\left(p_{t}-c\right) D_{t} \\
E\left(\pi_{r}\right)=\left(p_{s}-w\right) D_{s}=\Delta p D_{s}
\end{gathered}
$$

$\Delta p$ is numerical value between wholesale price and retail price which can be described as retailer's profit. Supplier is risk neutral, the utility function is the expected return, therefore:

$$
u\left(\pi_{a}\right)=E\left(\pi_{a}\right)=(w-c) D_{s}+\left(p_{t}-c\right) D_{t}
$$

According to Eq. (3):

$$
\begin{gathered}
\frac{\partial u(\pi)}{\partial w}=-2 b_{1} w+2 \theta p_{t}+(1-\delta) a+b_{1} c-\theta c-b_{1} \Delta p, \\
\frac{\partial u(\pi)}{\partial p_{t}}=-2 b_{2} p_{t}+2 \theta p_{s} w+\delta a-\theta c-\theta \Delta p .
\end{gathered}
$$

For $\frac{\partial^{2} u(\pi)}{\partial w^{2}}=-2 b_{1}<0, \frac{\partial^{2} u(\pi)}{\partial p_{\mathrm{t}}{ }^{2}}=-2 b_{2}<0$, optimal $w$ and $p_{t}$ exist, similar to the study of Wang et al. [14]:

$$
\left[\begin{array}{c}
w \\
p_{t}
\end{array}\right]=\boldsymbol{A}^{-1} \boldsymbol{B}, \quad \boldsymbol{A}=\left[\begin{array}{cc}
2 b_{1} & -2 \theta \\
-2 \theta & 2 b_{2}
\end{array}\right], \quad \boldsymbol{B}=\left[\begin{array}{c}
(1-\delta) a+b_{1} c-\theta c-b_{1} \Delta p \\
\delta a-\theta c-\theta \Delta p
\end{array}\right]
$$

Matrix $\boldsymbol{A}$ is positive definite and nonsingular matrix, so:

$$
\begin{gathered}
p_{t}=\frac{\theta a+\left(b_{1}-\theta\right) \delta a}{2\left(b_{1} b_{2}-\theta^{2}\right)}+\frac{c}{2} \\
w=\frac{\left(b_{2}-b_{2} \delta+\theta \delta\right) a}{2\left(b_{1} b_{2}-\theta^{2}\right)}+\frac{c-\Delta p}{2}
\end{gathered}
$$


Retailer is the adverse risk type, $k$ is the aversion risk coefficient, still using the mean variance theory, combined with the type (2), (3), (4) and (5), the utility function is:

$$
\operatorname{var}(\pi)=E\left\{[\pi-E(\pi)]^{2}\right\}=\frac{(1-\delta)^{2} \Delta p^{2}}{4} \sigma^{2}
$$

The utility function is defined by mean variance method, $u(\pi)=E(\pi)-k \sqrt{\operatorname{var}(\pi)}$ :

$$
u\left(\pi_{r}\right)=E\left(\pi_{r}\right)-k \sqrt{\frac{(1-\delta)^{2} \Delta p^{2}}{4} \sigma^{2}}
$$

$\frac{\partial^{2} u\left(\pi_{r}\right)}{\partial \Delta p^{2}}=-2 b_{1}<0, u\left(\pi_{r}\right)$ is the concave function about $\Delta p, \frac{\partial u\left(\pi_{r}\right)}{\partial \Delta p}=0$, so we obtain:

$$
\Delta p=\frac{(1-\delta)(a-k \sigma)-\left(b_{1}-\theta\right) c}{2 b_{1}}
$$

In type (5), we obtain:

$$
\begin{aligned}
& w=\frac{\left[(1-\delta)\left(b_{1} b_{2}+\theta^{2}\right)+2 b_{1} \theta \delta\right] a}{4 b_{1}\left(b_{1} b_{2}-\theta^{2}\right)}+\frac{\left(3 b_{1}-\theta\right) c+(1-\delta) k \sigma}{4 b_{1}} \\
& p_{s}=\frac{\left[(1-\delta)\left(3 b_{1} b_{2}-\theta^{2}\right)+2 b_{1} \theta \delta\right] a}{4 b_{1}\left(b_{1} b_{2}-\theta^{2}\right)}+\frac{\left(b_{1}+\theta\right) c-(1-\delta) k \sigma}{4 b_{1}}
\end{aligned}
$$

From the Eqs. (8) and (9) is evident that the wholesale price of retailer $w$ is proportional to $k$, and the retail price $p_{s}$ is inversely proportional to $k$, which indicates that risk-averse retailer can use the method of increasing wholesale price or reducing retail price in order to ensure maximum effectiveness. Retailer can coordinate better the relationship with both the supplier and the consumers by adjusting the prices and appropriately compressing the profits, so as to ensure the flexibility and efficiency of the retail channel.

As $p_{t}>w$, we can get:

$$
\frac{\left(b_{1} b_{2}-2 b_{1} \theta+\theta^{2}\right) a+\left(b_{1}-\theta\right)\left(b_{1} b_{2}-\theta^{2}\right) c+\left(b_{1} b_{2}-\theta^{2}\right) k \sigma}{\left(2 b_{1}{ }^{2}-4 b_{1} \theta+b_{1} b_{2}+\theta^{2}\right) a+\left(b_{1} b_{2}-\theta^{2}\right) k \sigma}<\delta<1
$$

When the share of direct sale channel satisfies Eq. (10), supplier can use dual-channel marketing strategy. Or else $p_{t} \leq w$, the advantages of the retail channels are not completely considered and do not corroborate to the actual situation.

Furthermore, we can get the optimal sales quantity and the excellent profit of the supply chain system:

$$
\begin{gathered}
D_{s}=\frac{(1-\delta)(a+k \sigma)-\left(b_{1}-\theta\right) c}{4} \\
D_{t}=\frac{\theta(1-\delta)(a-k \sigma)+\left(\theta^{2}-2 b_{1} b_{2}+b_{1} \theta\right) c+2 b_{1} \delta a}{4 b_{1}} \\
Q=D=\frac{a-\phi c}{4 b_{1} \xi_{2}}+\frac{(1-\delta)\left(b_{1}-\theta\right) k \sigma}{4 b_{1}}
\end{gathered}
$$


The Eqs. (11), (12) and (13) show that the optimal demand for retailer $D_{s}$ is proportional to $k$, while retailer sales price is inversely proportional to $k$, this indicates that the more risk adverse retailer has, the greater the demand for retail channel is. Risk-averse retailer often improves the order quantity to ensure maximum utility. The demand for direct marketing channel $D_{t}$ is inversely proportional to $k$, which indicates that the dominant retailer will increase the supply quantity to avoid risk, and causes the exclusion effect on direct channels of selling. The retailer's optimal demand $D$ is directly proportional to $k$, meaning that the averse risk makes retailer often increases the order quantity in order to avoid it, so that the supplier's sales of agricultural products can be improved. The supplier's optimal demand $Q$ is the same with the retailer's optimal demand $D$ and therefore the supplier can work out the supply plan according to retailer's demand.

Analyzing the price and the demand, we see that, in pursuit of greater utility, the retailer is more afraid of the risk as the higher price in the wholesale, means lower retail price and greater supply demand for retail channel. The supplier's direct selling price $p_{t}$ is not in relation to $k$; the wholesale price $w$ is proportional to $k$, the retail price $p_{s}$ is inversely proportional to $k$. In order to avoid risk, lower retail price are adjusted, which makes the market demand increase. On one hand, this makes bigger utility to the retailer, and on the other, the suppliers' agricultural products are promoted.

\section{RISK DECISION OF DUAL-CHANNEL UNDER DISTURBANCE}

Emergencies disrupt the normal operation of the supply chain and cause great harm. In order to facilitate quantitative analysis, we consider the changes in consumer demand under emergency, and the affect on the pricing of supply chain channels and the change of optimal output.

$$
\begin{gathered}
\tilde{D}_{s}=(1-\delta)(a+\Delta a)-b_{1} \tilde{p}_{s}+\theta \tilde{p}_{t} \\
\tilde{D}_{t}=\delta(a+\Delta a)-b_{2} \tilde{p}_{t}+\theta \tilde{p}_{s}
\end{gathered}
$$

Total supply chain demand:

$$
\tilde{D}=\tilde{D}_{s}+\tilde{D}_{t}=(a+\Delta a)-\left(b_{1}-\theta\right) \tilde{p}_{s}-\left(b_{2}-\theta\right) \tilde{p}_{t}
$$

If the actual supply demand from the supplier is lower than originally planned, the processing cost will be generated. If the actual demand is greater than originally planned supply quantity, the shortage cost will be produced, displayed as shortage cost $f_{1}$ and treatment cost $f_{2}$ of introducing factor with the assumption $f_{1}<c, f_{2}<c$. It is assumed that the losses due to disruptions are all caused by the supplier. Therefore, when unpredicted circumstances lead to demand disruptions, the expected return of the supply chain is:

$$
\begin{gathered}
E\left(\tilde{\pi}_{r}\right)=\Delta \tilde{p} \tilde{D}_{s} \\
E\left(\tilde{\pi}_{a}\right)=(\tilde{w}-c) \tilde{D}_{s}+\left(\tilde{p}_{t}-c\right) \tilde{D}_{t}-f_{l}(\tilde{D}-Q)^{+}-f_{2}(Q-\tilde{D})^{+}
\end{gathered}
$$

In the Eq. (18) $(x)^{+}=\max \{0, x\}$, the first part represents the revenue of retail channel under demand disruptions. The second part represents the direct docking channel gains, the third part represents the shortage losses when market demand is greater than the original supply plan due to the demand disruptions, the fourth part represents the processing losses when market demand is less than the original supply plan due to the demand disruptions. According to the actual situation, the shortage and processing cost will not be simultaneous. 
When $\Delta a>0$, supplier is risk neutral, the expected profit of the supply chain is utility function:

$$
\begin{gathered}
u\left(\tilde{\pi}_{a}\right)=E\left(\tilde{\pi}_{a}\right)=(\tilde{w}-c) \tilde{D}_{s}+\left(\tilde{p}_{t}-c\right) \tilde{D}_{t}-f_{1}(\tilde{D}-Q) \\
\text { s.t. } \tilde{D} \geq Q
\end{gathered}
$$

When $\Delta a<0$, the utility function is:

$$
\begin{gathered}
u\left(\tilde{\pi}_{a}\right)=E\left(\tilde{\pi}_{a}\right)=\left(\tilde{p}_{s}-c\right) \tilde{D}_{s}+\left(\tilde{p}_{t}-c\right) \tilde{D}_{t}-f_{2}(Q-\tilde{D}) \\
\text { s.t. } \tilde{D} \leq Q
\end{gathered}
$$

According to the Eqs. (14), (15), (19) and (20), $u(\tilde{\pi})$ is the joint concave function of $\tilde{p}_{t}$ and $\tilde{w}$, the constraints are linear, so $u(\tilde{\pi})$ has a unique optimal solution, the Lagrange multiplier is introduced, discussing two cases, $\lambda>0$ and $\lambda=0$, the Kuhn-Tucker condition is:

$$
\begin{aligned}
& \left\{\begin{array}{l}
\frac{\partial u(\tilde{\pi})}{\partial \tilde{p}_{t}}-\lambda \frac{\partial(\tilde{D}-Q)}{\partial \tilde{p}_{t}}=0 \\
\frac{\partial u(\tilde{\pi})}{\partial \tilde{w}}-\lambda \frac{\partial(\tilde{D}-Q)}{\partial \tilde{w}}=0 \\
\lambda(\tilde{D}-Q)=0 \\
\tilde{D} \geq Q
\end{array}\right. \\
& \left\{\begin{array}{l}
\frac{\partial u(\tilde{\pi})}{\partial \tilde{p}_{t}}-\lambda \frac{\partial(Q-\tilde{D})}{\partial \tilde{p}_{t}}=0 \\
\frac{\partial u(\tilde{\pi})}{\partial \tilde{w}}-\lambda \frac{\partial(Q-\tilde{D})}{\partial \tilde{w}}=0 \\
\lambda(Q-\tilde{D})=0 \\
Q \geq \tilde{D}
\end{array}\right.
\end{aligned}
$$

As $\tilde{p}_{t}>\tilde{w}, \tilde{D} \leq Q, \tilde{D} \geq Q$, further conclusions can be obtained:

$$
\begin{aligned}
& R_{1}=\left\{(\delta, \Delta a) \mid \frac{\left(b_{1} b_{2}-2 b_{1} \theta+\theta^{2}\right)(a+\Delta a)+\left(b_{1} b_{2}-\theta^{2}\right)\left[k \sigma+\left(b_{1}-\theta\right)\left(c+f_{1}\right)\right]}{(a+\Delta a)\left(2 b_{1}{ }^{2}-4 b_{1} \theta+b_{1} b_{2}+\theta^{2}\right)+\left(b_{1} b_{2}-\theta^{2}\right) k \sigma}<\delta<1, \Delta a \geq \varphi f_{1}\right\}, \\
& R_{2}=\left\{(\delta, \Delta a) \mid \frac{2 b_{1}\left(b_{2}-\theta\right)(a+\Delta a)-\left(b_{1}{ }^{2}-\theta^{2}\right) a+\left(b_{1}-\theta\right) \xi_{1} c+2\left(b_{1} b_{2}-\theta^{2}\right) k \sigma}{2 b_{1}\left(b_{1}+b_{2}-2 \theta\right)(a+\Delta a)+\left(b_{1}-\theta\right)^{2} a+2\left(b_{1} b_{2}-\theta^{2}\right) k \sigma}<\delta<1,-\varphi f_{2}<\Delta a<\varphi f_{1}\right\}, \\
& R_{3}=\left\{(\delta, \Delta a) \mid \frac{\left(b_{1} b_{2}-2 b_{1} \theta+\theta^{2}\right)(a+\Delta a)+\left(b_{1} b_{2}-\theta^{2}\right)\left[k \sigma+\left(b_{1}-\theta\right)\left(c-f_{2}\right)\right]}{(a+\Delta a)\left(2 b_{1}^{2}-4 b_{1} \theta+b_{1} b_{2}+\theta^{2}\right)+\left(b_{1} b_{2}-\theta^{2}\right) k \sigma}<\delta<1, \Delta a \leq-\varphi f_{2}\right\}
\end{aligned}
$$

According to the Eqs. (21) and (22), we get:

$$
\Delta \tilde{p}=\left\{\begin{array}{l}
\frac{(1-\delta)(a+\Delta a-k \sigma)-\left(b_{1}-\theta\right)\left(c+f_{1}\right)}{2 b_{1}} \\
\frac{\xi_{2}\left(b_{1}-\theta\right)(a-\varphi c)}{4 b_{1}\left(b_{1} b_{2}-\theta^{2}\right)}+\frac{\left(b_{2}-\theta-b_{1} \delta-b_{2} \delta+2 \theta \delta\right)(a+\Delta a)}{2\left(b_{1} b_{2}-\theta^{2}\right)}-\frac{(1-\delta) k \sigma}{2 b_{1}} \\
\frac{(1-\delta)(a+\Delta a-k \sigma)-\left(b_{1}-\theta\right)\left(c-f_{2}\right)}{2 b_{1}} \\
(\delta, \Delta a) \in R_{1} \quad(\delta, \Delta a) \in R_{2} \quad(\delta, \Delta a) \in R_{3}
\end{array}\right.
$$


According to the Eq. (23), the profit of the retailer $\Delta \tilde{p}$ is inversely proportional to $k$, which indicates that the retailer makes decisions based on the adverse risk, in order to ensure the maximum utility; the more afraid of risk the retailer is, the lower profit gets. In the region $R_{1}$ and $R_{3}, \Delta \tilde{p}$ is directly proportional to $\Delta a$, at the same time, there is a shortage or processing cost. In the region $R_{2}, \Delta \tilde{p}$ is not related to $f_{1}, f_{2}$, the supplier can balance the retail channel by adjusting the direct channel, and the cost of processing or the shortage is not generated.

Further conclusions can be obtained:

$$
\tilde{w}=\left\{\begin{array}{c}
w+\frac{\left[\left(b_{1} b_{2}-2 b_{1} \theta+\theta^{2}\right)(1-\delta)+2 b_{1} \theta\right] \Delta a}{4 b_{1}\left(b_{1} b_{2}-\theta^{2}\right)}+\frac{\left(3 b_{1}-\theta\right) f_{1}}{4 b_{1}} \\
w+\frac{\left(2 b_{1}{ }^{2}-4 b_{1} \theta+3 b_{1} b_{2}-\theta^{2}\right) \Delta a}{4\left(b_{1} b_{2}-\theta^{2}\right)\left(b_{1}+b_{2}-2 \theta\right)}-\frac{\left(4 b_{1}{ }^{2}-4 b_{1} \theta-b_{1} b_{2}+\theta^{2}\right)(1-\delta) \Delta a}{8 b_{1}\left(b_{1} b_{2}-\theta^{2}\right)} \\
w+\frac{\left[\left(b_{1} b_{2}-2 b_{1} \theta+\theta^{2}\right)(1-\delta)+2 b_{1} \theta\right] \Delta a}{4 b_{1}\left(b_{1} b_{2}-\theta^{2}\right)}-\frac{\left(3 b_{1}-\theta\right) f_{2}}{4 b_{1}} \\
(\delta, \Delta a) \in R_{1} \quad(\delta, \Delta a) \in R_{2} \quad(\delta, \Delta a) \in R_{3}
\end{array}\right.
$$

As $\tilde{p}_{s}=\tilde{w}+\Delta \tilde{p}$, further conclusions can be obtained:

$$
\tilde{p}_{s}=\left\{\begin{array}{l}
p_{s}+\frac{\left[\left(b_{1} b_{2}-2 b_{1} \theta+\theta^{2}\right)(1-\delta)+2 b_{1} \theta\right] \Delta a}{4 b_{1}\left(b_{1} b_{2}-\theta^{2}\right)}+\frac{(1-\delta) \Delta a}{2 b_{1}}+\frac{\left(b_{1}+\theta\right) f_{1}}{4 b_{1}} \\
p_{s}-\frac{\left(6 b_{2}{ }^{2}-18 b_{2} \theta+3 b_{1} b_{2}+13 \theta^{2}-4 b_{1} \theta\right) \delta \Delta a}{8\left(b_{1} b_{2}-\theta^{2}\right)\left(b_{1}+b_{2}-2 \theta\right)}+\frac{\left(6 b_{2}{ }^{2}+5 b_{1} b_{2}-\theta^{2}\right) \Delta a}{8\left(b_{1} b_{2}-\theta^{2}\right)\left(b_{1}+b_{2}-2 \theta\right)} \\
+\frac{\left(b_{1}^{2}-2 b_{1} \theta+\theta^{2}-\theta^{2} \delta+2 b_{1} \theta \delta\right)}{4 b_{1}\left(b_{1} b_{2}-\theta^{2}\right)}-\frac{\left(b_{1}-\theta\right)^{3}}{4 b_{1}\left(b_{1} b_{2}-\theta^{2}\right)} \\
p_{s}+\frac{\left[\left(b_{1} b_{2}-2 b_{1} \theta+\theta^{2}\right)(1-\delta)+2 b_{1} \theta\right] \Delta a}{4 b_{1}\left(b_{1} b_{2}-\theta^{2}\right)}+\frac{(1-\delta) \Delta a}{2 b_{1}}-\frac{\left(b_{1}+\theta\right) f_{2}}{4 b_{1}} \\
(\delta, \Delta a) \in R_{1} \quad(\delta, \Delta a) \in R_{2} \quad(\delta, \Delta a) \in R_{3} \\
\Delta p_{t}=\tilde{p}_{t}-p_{t} \quad(\delta, \Delta a) \in R_{1} \quad(\delta, \Delta a) \in R_{2} \quad(\delta, \Delta a) \in R_{3}
\end{array}\right.
$$

According to the Eqs. (25) and (26), under the disruption of the market demand, when $\Delta p_{s}\left(\Delta p_{s}=\tilde{p}_{s}-p_{s}\right)$ and $\Delta p_{t}\left(\Delta p_{t}=\tilde{p}_{t}-p_{t}\right)$ are not related to $k$, it is inevitable that the demand disruption brings the change of channel price. Using Eqs. (14), (15) and (16), we get:

$$
\begin{aligned}
& D_{s}=\left\{\begin{array}{l}
D_{s}+\frac{(1-\delta) \Delta a-\left(b_{1}-\theta\right) f_{1}}{4} \\
D_{s}+\frac{\left(b_{2}-\theta-b_{1} \delta-b_{2} \delta+2 \theta \delta\right) \Delta a}{4\left(b_{1}+b_{2}-2 \theta\right)} \\
D_{s}+\frac{(1-\delta) \Delta a+\left(b_{1}-\theta\right) f_{2}}{4}
\end{array}\right. \\
& (\delta, \Delta a) \in R_{1} \quad(\delta, \Delta a) \in R_{2} \quad(\delta, \Delta a) \in R_{3}
\end{aligned}
$$




$$
\begin{gathered}
\tilde{D}_{t}=\left\{\begin{array}{l}
D_{t}+\frac{\left(\theta+2 b_{1} \delta-\theta \delta\right) \Delta a-\left(2 b_{1} b_{2}-\theta^{2}-b_{1} \theta\right) f_{1}}{4 b_{1}} \\
D_{t}-\frac{\left(b_{2}-\theta-b_{1} \delta-b_{2} \delta+2 \theta \delta\right) \Delta a}{4\left(b_{1}+b_{2}-2 \theta\right)} \\
D_{t}+\frac{\left(\theta+2 b_{1} \delta-\theta \delta\right) \Delta a+\left(2 b_{1} b_{2}-\theta^{2}-b_{1} \theta\right) f_{2}}{4 b_{1}}
\end{array}\right. \\
(\delta, \Delta a) \in R_{1}(\delta, \Delta a) \in R_{2}(\delta, \Delta a) \in R_{3} \\
\tilde{Q}=\tilde{D}=\left\{\begin{array}{c}
D+\frac{\xi_{2} \Delta a-\xi_{1} f_{1}}{4 b_{1}} \\
D \\
D+\frac{\xi_{2} \Delta a+\xi_{1} f_{2}}{4 b_{1}}
\end{array} \quad(\delta, \Delta a) \in R_{2} \quad(\delta, \Delta a) \in R_{3}\right.
\end{gathered}
$$

According to the Eq. (29), the change of supply chain decision is related to the disturbance $\Delta a$. When the supply chain is disturbed in $\left(-\varphi f_{2}, \varphi f_{1}\right)$ the optimal demand is still significant. But beyond the range of disturbance $\left(-\varphi f_{2}, \varphi f_{1}\right)$ supplier will adjust the initial supply quantity accordingly. The demand disturbance of the supply chain in $\left(-\varphi f_{2}, \varphi f_{1}\right)$ through the adjustment of the direct channel, can balance the retailer channel but beyond the range of the disturbance $\left(-\varphi f_{2}, \varphi f_{1}\right)$, the retailer will pursue maximum utility, and then, the supplier will adjust the number of initial supplies to meet the retailer channel.

Further discussion is made according to the Eqs. (27) and (28). The dual-channel change with the demand disruption, when it is in the interval $\left(-\varphi f_{2}, \varphi f_{1}\right)$, regardless of the market share $\delta$, the sales change coefficient of two channels will be the same, which indicates the equal amount of demand transfers between the two channels. When the demand disruption exceeds the range $\left(-\varphi f_{2}, \varphi f_{1}\right)$, the sales quantity of two sales channels is affected by the market share $\delta$.

The optimal sales volume and the optimal total demand value of the system are not only related to the market share $\delta$, but also to the scope of $\delta$. When $(\delta, \Delta a) \in R_{2}$, the set variation coefficient of the impact of demand disturbance on retailer channel and direct channel are $\tau_{1}$ and $\tau_{2}$, respectively; $\tau_{1}=-\tau_{2}=\frac{b_{2}-\theta-b_{1} \delta-b_{2} \delta+2 \theta \delta}{4\left(b_{1}+b_{2}-2 \theta\right)}$, the demand change rate of the two sales channels is same, but offset in the system. $\tau_{1}$ is inversely proportional to $\delta$, that is, the larger the $\delta$, the smaller the $\tau_{1}$.

When $(\delta, \Delta a) \in R_{1},(\delta, \Delta a) \in R_{3}$, the set variation coefficient of the impact of demand disturbance on retailer channel and direct channel are $\tau_{3}$ and $\tau_{4}$.

$$
\begin{gathered}
\tau_{3}=\frac{\partial\left(\tilde{D}_{s}-D_{s}\right)}{\partial \Delta a}=\frac{1-\delta}{4}, \tau_{4}=\frac{\partial\left(\tilde{D}_{t}-D_{t}\right)}{\partial \Delta a}=\frac{\theta+2 b_{1} \delta-\theta \delta}{4 b_{1}}, \\
\tau_{3}-\tau_{4}=\frac{1-\delta}{4}-\frac{\theta+2 b_{1} \delta-\theta \delta}{4 b_{1}}=\frac{\left(b_{1}-\theta\right)-\left(3 b_{1}-\theta\right) \delta}{4 b_{1}}, \\
\delta^{\prime}<\frac{b_{1}-\theta}{3 b_{1}-\theta}, \quad \tau_{3}>\tau_{4}, \quad \delta^{\prime}=\frac{b_{1}-\theta}{3 b_{1}-\theta}, \quad \tau_{3}=\tau_{4}, \quad \delta^{\prime}>\frac{b_{1}-\theta}{3 b_{1}-\theta}, \quad \tau_{3}<\tau_{4} .
\end{gathered}
$$


For:

$$
\begin{gathered}
\delta>\frac{\left(b_{1} b_{2}-2 b_{1} \theta+\theta^{2}\right)(a+\Delta a)+\left(b_{1} b_{2}-\theta^{2}\right)\left[k \sigma+\left(b_{1}-\theta\right)\left(c+f_{1}\right)\right]}{(a+\Delta a)\left(2 b_{1}^{2}-4 b_{1} \theta+b_{1} b_{2}+\theta^{2}\right)+\left(b_{1} b_{2}-\theta^{2}\right) k \sigma}, \\
\delta^{\prime}-\delta=\frac{b_{1}-\theta}{3 b_{1}-\theta}-\frac{\left(b_{1} b_{2}-2 b_{1} \theta+\theta^{2}\right)(a+\Delta a)+\left(b_{1} b_{2}-\theta^{2}\right)\left[k \sigma+\left(b_{1}-\theta\right)\left(c+f_{1}\right)\right]}{(a+\Delta a)\left(2 b_{1}{ }^{2}-4 b_{1} \theta+b_{1} b_{2}+\theta^{2}\right)+\left(b_{1} b_{2}-\theta^{2}\right) k \sigma} \\
=\frac{-\left(b_{1}-\theta\right)\left(3 b_{1}-\theta\right)\left(b_{1} b_{2}-\theta^{2}\right)\left(c+f_{1}\right)-2 b_{1}^{2}\left(b_{2}-b_{1}\right)(a+\Delta a)-2 b_{1}\left(b_{1} b_{2}-\theta^{2}\right) k \sigma}{\left(3 b_{1}-\theta\right)(a+\Delta a)\left(2 b_{1}{ }^{2}-4 b_{1} \theta+b_{1} b_{2}+\theta^{2}\right)+\left(b_{1} b_{2}-\theta^{2}\right) k \sigma}<0 .
\end{gathered}
$$

Considering $\delta^{\prime}>\left(b_{1}-\theta\right) /\left(3 b_{1}-\theta\right)$, with $\tau_{3}<\tau_{4}$ the impact on retailer channel by demand disruptions is lower than the one on the direct channel. The retailer of agricultural products plays a leading role in the dual-channel supply chain, and the ability of anti disturbance is relatively large, which is in accordance with the actual situation. When the demand disturbance is large, the direct selling channel is more volatile, so more attention should be paid.

\section{EXAMPLE ANALYSES}

In order to verify the results discussed in this paper and find the potential change rules, numerical examples are discussed. Considering the impact of aversion risk and unpredicted disruptions, the relevant parameters are set according to the conditional assumptions.

Take $a=200, \sigma=20, b_{1}=4, b_{2}=5, \theta=1, f_{1}=f_{2}=2, c=3$.

Here $\delta_{0}=3 / 5, \delta^{\prime}=1 / 4$, take $\delta=0.4$.

According to Table 1, we can see the retailer's profit $\Delta p$ is inversely proportional to $k$, the retailer's wholesale price $w$ is proportional to $k$, and the retail price $p_{s}$ inversely proportional to $k$; the slopes of $p_{s}, \tilde{p}_{s}, \Delta p, \Delta \tilde{p}, w, \tilde{w}$ to $k$ are equal, which shows that the relationship between the coefficient of price and aversion risk, is not disturbed by external disturbances; $p_{t}, \tilde{p}_{t}$ has no relation with $k$, indicating that the direct channel pricing by the supplier master is not affected by the risk attitude of the retailer. The optimal $D$ and $\tilde{D}$ are directly proportional to the risk aversion coefficient of retailer. The robust area is (-470/31, 470/31), where the demand change rate of the two sales channels is the same, $\tau_{1}=\tau_{2}$, while out of the robust area the direct channel is more volatile, $\tau_{3}<\tau_{4}$. In the robust area, the optimal supply from the suppliers can remain unchanged, while out of the robust area, the optimal supply from the suppliers will adjust to match the optimal demand of the retailer.

According to Figure 2, in the robust area, the change rate of $\Delta p$ is smaller than outside the robust area, showing that the retailer's profit change along with $\Delta a$ slowly under steady state, the profits of retailers vary greatly under unpredicted circumstances, conforming the actual situation. That $\Delta p$ is inversely proportional to $k$, indicates that the risk-averse retailer often compresses profit margins to avoid the risk. 
Table 1 Optimal decision of supply chain at $\delta=0.4$

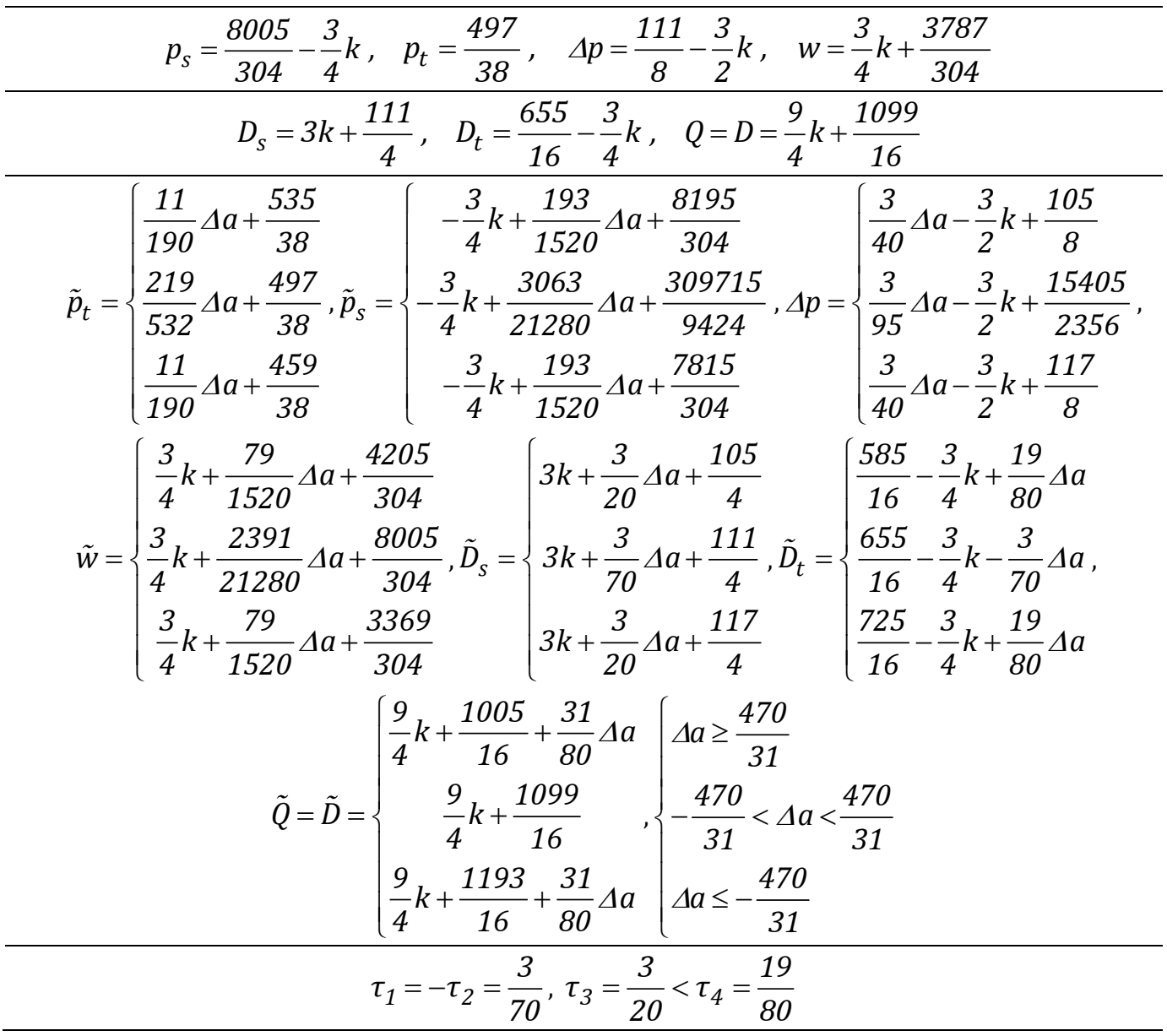

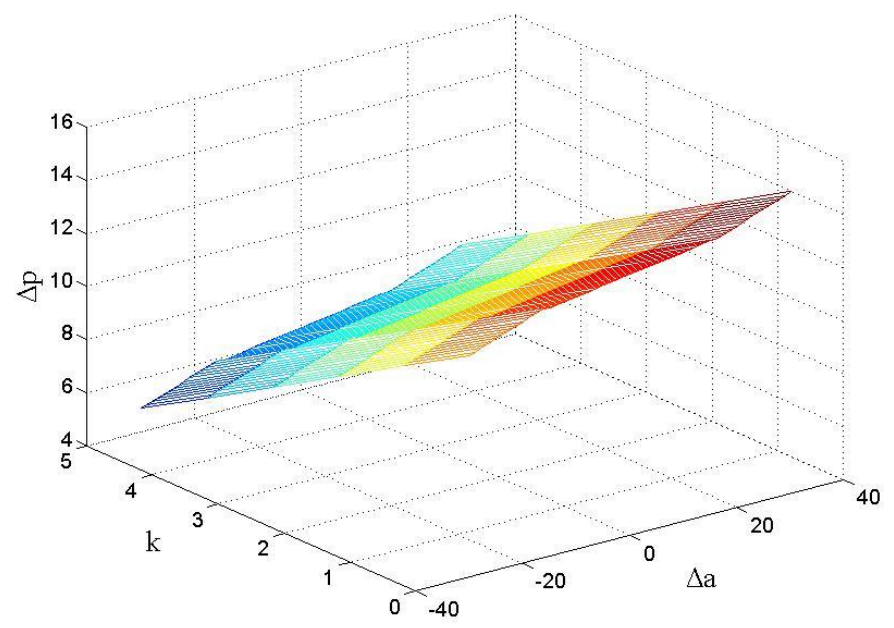

Fig. 2 Relation diagram of $\Delta p, \Delta a$ and $k$ under emergency 


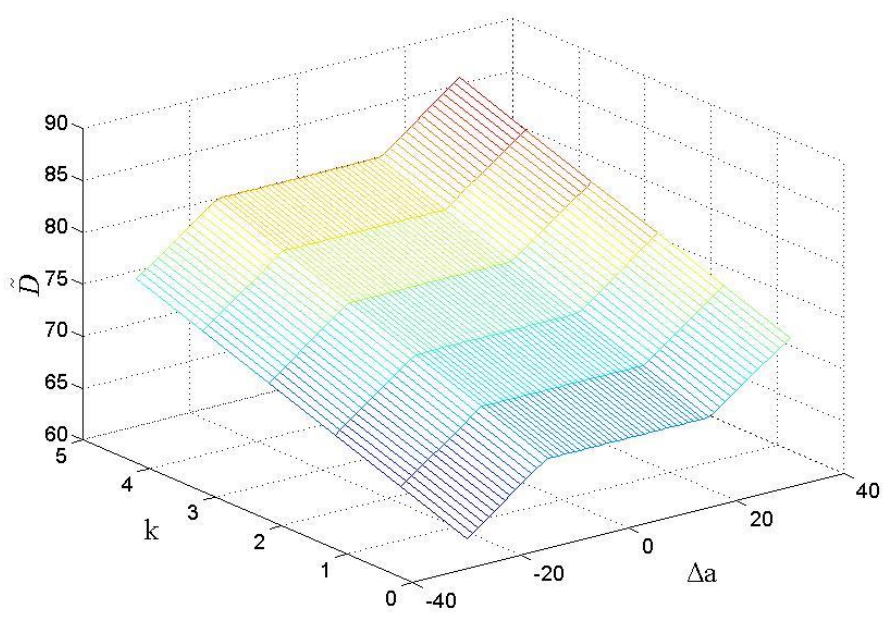

Fig. 3 Relation diagram of $\tilde{D}, \Delta a$ and $k$ under emergency

According to Figure 3, the supplier's optimal demand $\tilde{D}$ is stable in the robust area, increases with the $\Delta a$ at both ends of the interval, showing that the supplier won't change the initial supply quantity in the robust area, supplier will adjust the initial supply quantity accordingly beyond the robust area. $\tilde{D}$ is directly proportional to $k$, showing that the adverse risk of retailer often increases the order quantity to avoid the risk, so that the sales of agricultural products at the supplier can be improved.

\section{CONCLUSIONS}

Agricultural supplier adopts the dual-channel supply chain model where retailer plays a leading role. Mean variance method is used to consider risk attitude in supply chain. In view of the market demand disturbance caused by emergency, the decision methods for the optimal supply and pricing of the supply chain are as follows.

The retailer's demand is proportional to the risk aversion coefficient, the wholesale price is proportional to the risk aversion coefficient, and the retailer's retail price is inversely proportional to the risk aversion coefficient. Analyzing the price and demand, retailer, in pursuit of great utility, is more afraid of risks such as higher wholesale price, that lead to lower retail price and greater supply demand of retail channels. Risk-averse retailer can adopt the method of compressing its own profit space and expanding the market demand, in addition, he/she can establish a stronger relationship with both the supplier and the consumers to ensure the flexibility and efficiency of the retail channel. The supplier's optimal supply is equal to the retailer's optimal demand, which is directly proportional to the risk aversion coefficient. The retailer's optimal demand is rising under the influence of risk aversion, indicating that the supply chain evades the risk by increasing the order quantity. The optimal supply from the suppliers will be adjusted to match the optimal demand of the retailer.

This paper reveals the robust area of supplier. When the market demand disturbance is small, the supplier does not adjust the initial supply quantity. When the disturbance is large, the supplier will adjust the initial supply quantity.

When the share of direct sale channel is higher than a certain proportion, the dual-channel supply chain can operate normally. When the unpredicted circumstances cause the demand disturbance, the market demand of the retail channel and direct channel changes with the 
disruption. In the robust region, the demand rate of two sales channels is same; but outside it, the retail channel is less affected by the demand disturbance than the direct channel.

Further study is needed on how to deal with the risk of the supply chain, and how to share the risk of loss.

\section{ACKNOWLEDGMENTS}

The paper is part of the project supported financially by The National Natural Science Fund Project (no. 71171174), Hebei Province Natural Science Fund Project (no. G2014203219). The authors acknowledge such a support.

\section{REFERENCES}

[1] G. Cai, Channel Selection and Coordination in Dual-Channel Supply Chains, Journal of Retailing, Vol. 86, No. 1, pp. 22-36, 2010. Doi.org/10.1016/j.jretai.2009.11.002

[2] X.J. Pu, D.L. Jin, The operational efficiency measurement of Agro-food supply chains: the Single Farmer-Supermarket direct purchase vs. dual channel, Chinese Journal of Management Science, Vol. 25, No. 1, pp. 98-105, 2017. http://dx.doi.org/10.16381/j.cnki.Issn.1003-207x.2017.01.011

[3] J. Li, X.F. Liu, J. Wu, F.M. Yang, Coordination of Supply Chain with a Dominant Retailer under Demand Disruptions, Mathematical Problems in Engineering, No. 1, pp. 1-10, 2014. http://dx.doi.org/10.1155/2014/854681

[4] D.C. Xie, H. Chen, Coordinating Dual-Channel supply chain under price mechanism with production cost disruption, Management Science and Engineering, Vol. 9, No. 2, pp. 1-7, 2015. http://dx.doi.org/10.3968/6591

[5] P. Zhang, Y. Xiong, Z. Xiong, Coordination of a dual-channel supply chain after demand or production cost disruptions, International Journal of Production Research, Vol. 53, No. 10, pp. 3141-3160, 2015. http://dx.doi.org/10.1080/00207543.2014.975853

[6] Z.T. Cheng, D.W. Zhao, Economics S O. Literature review on risk evaluation of agricultural product supply chain, Science-Technology and Management, Vol. 17, No. 6, pp. 49-53, 2015. http://dx.doi.org/10.16315/j.stm.2015.06.009

[7] S. Sarykalin, G. Serraino, S. Uryasev, Value-at-risk vs. conditional value-at-risk in risk management and optimization, In Tutorials in operations research, Informs, pp. 270-294, 2008. https://dx.doi.org/10.1287/educ.1080.0052

[8] J.P. Wang, D.Q. Yao, Z.L. Yang, Risk-averse retailer's two order supply chain decision model, Control and Decision, Vol. 31, No. 10, pp. 1811-1816, 2016.

http://dx.doi.org/10.13195/j.kzyjc.2015.1383

[9] T. Sawik, On the risk-averse optimization of service level in a supply chain under disruption risks, International Journal of Production Research, Vol. 54, No. 1, pp. 98-113, 2015. http://dx.doi.org/10.1080/00207543.2015.1016192

[10] X.G. Cao, B.R. Zheng, H.S. Xia, Analysis on closed-loop supply chain network equilibrium with risk-averse retailers, Control and Decision, Vol. 29, No. 4, pp. 659-665, 2014. http://dx.doi.org/10.13195/j.kzyjc.2012.1851 
[11] B. Yan, Z. Jin, Y. Liu, J. Yang, Decision on risk-averse dual-channel supply chain under demand disruption, Communications in Nonlinear Science and Numerical Simulation, Vol. 55, pp. 206-24, 2018. http://dx.doi.org/10.1016/j.cnsns.2017.07.003

[12] B. Li, P.W. Hou, P. Chen, Q.H. Li, Pricing strategy and coordination in a dual-channel supply chain with a risk-averse retailer, International Journal of Production Economics, Vol. 178, pp. 154-68, 2016. http://dx.doi.org/10.1016/j.ijpe.2016.05.010

[13] M. Liu, E. Cao, C.K. Salifou, Pricing strategies of a dual-channel supply chain with risk aversion, Transportation Research Part E: Logistics and Transportation Review, Vol. 90, pp. 108-20, 2016. http://dx.doi.org/10.1016/j.tre.2015.11.007

[14] H. Wang, J. Zhou, Competition and risk aversion to dual-channel and the impact of supply chain decisions, Journal of Management Science, Vol. 23, No. 1, pp. 10-17, 2010. http://dx.doi.org/10.3969/j.issn.1672-0334.2010.01.002

[15] M.L. Xu, X.Z. Nie, H.Y. Jian, Pricing decision of dual-channel supply chain under different risk preferences, Control and Decision, Vol. 31, No. 1, pp. 91-98, 2016. http://dx.doi.org/10.13195/j.kzyjc.2014.1335

[16] S. Huang, C. Yang, X. Zhang, Pricing and production decisions in dual-channel supply chains with demand disruptions, Computers \& Industrial Engineering, Vol. 62, No. 1, pp. 70-83, 2012. http://dx.doi.org/10.1016/j.cie.2011.08.017 